\title{
A New Paradigm in Traditional Human Resource Management Practices
}

\author{
Joe Duke II $^{1} \&$ Ekpo Nya Udono ${ }^{1}$ \\ ${ }^{1}$ Department of Business Management, University of Calabar, Calabar, Nigeria \\ Correspondence: Joe Duke II, Department of Business Management, University of Calabar, Calabar, Nigeria. \\ E-mail: joedukell@yahoo.com
}

Received: March 19, 2012 Accepted: May 2, 2012 Online Published: May 24, 2012

doi:10.5539/jms.v2n2p158 URL: http://dx.doi.org/10.5539/jms.v2n2p158

\begin{abstract}
This paper identifies and proposes a number of approaches and practices that are designed to help organizations grapple with new work-place realities, the impact of globalization and international competition. The proposed measures signal a shift in some of the traditional human resource management practices, which are increasingly becoming inadequate. The measures are mainly focused on promoting new work-place cultures, organizational language, multi-skilling and customer focus. The researchers however conclude that a number of tested and established human resource management practices need to be combined with the new paradigm in order to achieve significant productivity improvements that can lead to widespread superior corporate performance. The study suggests further research of empirical flavour in order to establish the effectiveness of the commendatory propositions made.
\end{abstract}

Keywords: human resource management, human resource practices, human capital

\section{Background}

There is a growing consensus that the key to superior corporate performance lies within the milieu of the human elements of an organization. Without doubt, human beings, more than any other set of resources, determine the success or failure of organizations. For instance, in any private or government, profit or not-for-profit establishment, it is people that set the agenda, objectives and strategies; they create, design, produce and deliver the goods and services and control their quality; they procure, allocate and distribute financial resources; and, they market and sell the end products or services of the organization. So central is the role of people that it can safely be argued that they are the most influential and responsible resources for the efficiency and effectiveness of an organization (Milkovich \& Boudreau, 2004). At the societal level, it is people who are equally responsible for policy-making and implementation, program and project design and implementation, as well as other socio-economic activities required for the smooth running of societies and systems. Indeed, human resources (HR) have no credible or perfect substitutes, as it is difficult to comprehend any other resource or element that can match the abilities, talents, skills and motivation of people to deliver on organizational requirements (Noe, Hollenbeck, Gerhart \& Wright, 2004). This realism puts added pressure on the managers of the human resources, just as it raises stakeholders' expectation. At the firm or micro level and societal or macro levels, the quality of the human resources, in terms of their skills, knowledge, training, experience, flexibility, adaptability and insights, is what determines the value of this resource class. As such, the higher the quality of the human resources, the more productive and competitive the people, the organizations they work for and the society become. The sum of the collective productivity of human resources in organizations within and across industry sectors therefore represents a critical economic development mechanism.

A discussion of the management of human resources in the twenty first century assumes a new complexity owing to the fresh realities surrounding people's needs and demands, organizational stakeholder's expectations, workplace dynamics and other emerging issues. As in other aspects of management, virtually all known principles and assumptions of managerial practice have been called into question in recent times (Lancourt \& Savage, 1995). To begin with, the typically traditional approaches and tools for managing the human content of the organization have become inadequate, moribund and even inappropriate in today's business environment. The changing nature of work, owing largely to: the rapid development in technology; productivity concerns of investors and other corporate stakeholders; stricter government regulation and enforcement; a shift from 
industrial economy to a knowledge-based one; and, the expectations and pressures of employees at the workplace have all made this so. In addition, growing consumer sophistication and discernment, intense intra-industry competition and rivalry, and the impact of globalization all mean that for any organization to survive, grow and thrive, its human resource management vehicle needs to drive in a different direction and gear. In view of this, managing the human assets effectively demands new attitudes, perspectives and competencies that largely focus on encouraging and enhancing creativity and innovation across the organization. This widespread innovation, amongst other things, is the basis for creating and transforming organizations into engines of corporate and societal growth and development.

In the light of these recent developments, our main objective in this conceptual paper is to identify new perspectives and approaches that have the potential of helping firms enhance the value of their human capital. We therefore propose that firms that embrace and adopt these new approaches are the ones that will heave themselves above their rivals, dominate their respective markets and position themselves as world-class. We commence our thesis by examining the traditional human resource management practices. This lays the foundation for examining the HR manager's role in organizations. We then identify new paradigms for managing an organization's workforce and then discuss a number of emerging concepts and practices of human resource management designed to guide HR managers in their role.

\section{An Overview of Human Resource Management Framework}

Put simply, human resource management (HRM) is that part of the management process that specializes in the management of people in work organizations (Bratton \& Gold, 1999). It consists of a series of decisions that concern employees and employers. Human resource management is primarily intended to influence the effectiveness of employees and employers, and it affects many constituencies and has ramifications for the overall success of the system (Milkovich \& Boudreau, 2004). By determining who works for a firm, human resource management impacts significantly on organizational performance, which is often measured by profitability or cost-efficiency, product or service quality and delivery, and customer satisfaction. Where human resource management practices are effective, employees and customers tend to be more satisfied and the organization becomes more productive, while developing a favorable reputation for itself in the market (Noe, Hollenbeck, Gerhart \& Wright, 2004). In view of this, the real challenge for the human resource manager is how to attract, motivate and retain good people (Oyesola, 2011).

The framework for the management of human resources consists of five main activity areas that operate in an overlapping continuum: planning; staffing; compensation; employee training and development; and, employee relations. Performance management exists as a cross-cutting process that has relevance and influence on all the main activities.

Planning as the first and basic activity of HRM captures all actions involving the gathering of data and information from both the organization's internal and external environments (consisting of the economic; socio-cultural, government legislation and regulation, and unions, industry and market, geographic, population and demographic, technological, and global sub-systems of the operating environment), analysis and interpretation of the implications of the changes in the factors surrounding these sub-systems. It also consists of analysis, synthesis and design of work, formulation of compliance rules and provision of support for the organizational strategies. Proper human resource planning helps reduce to the barest minimum the uncertainties of environmental threats, while also helping the organization take advantage of emerging opportunities.

The Staffing activities draw directly from the results of planning, as they necessarily comprise actions geared towards ensuring adequacy of the quality and numbers of people. It is about attracting and retaining the right number and skills that should help in the achievement of organizational objectives. Staffing essentially involves planning for staffing, recruitment, selection and placement of human elements within the organization. Where the human resource manager focuses on developing staffing plans with emphasis on quantitative analysis that express the organization's people requirements in terms of figures and types of skills needed, planning for staffing is considered to be hard. Whereas, planning is viewed as soft where the planner downplays numbers and rather focuses on staffing on the basis of the right type of attitude, behavior, commitment and high levels of intrinsic motivation. Of all HRM activities, staffing has the most far-reaching implications for an organization. Its ramifications encompass operating cost (and therefore, profitability), in the sense that employing the right types of people can translate into savings arising from efficiency and productivity; or losses necessitated by frequent retraining. Similarly, severance and litigation costs can sometimes severely affect an organization when it becomes imperative that an employee who does not fit the needs of the system must be dropped. Beyond this, staffing provides an opportunity for an organization to secure competitive edge over its rivals using its pool of 
skilled people.

Compensation includes all forms of financial returns, tangible services and benefits an employee gets rewarded with in return for the services he renders as part of his covenant with the organization. This pervasive and sensitive activity centers on the amount of pay an employee should receive for the work done. Managers here are typically confronted with the dilemma of making pay decisions based on either the nature of work; the ability, knowledge, skills and experience of the employee; the financial condition of the organization or the health of the industry or economy; the value of the goods or services the employee creates; or, on the employee's or their union's negotiating power. The HR manager needs to balance the organization's need to minimize wage bill expenses and employees' demands and expectations.

Employee training and development includes training, upgrading, re-tooling and skills-optimization activities that are carried out with a view to enhancing employees' performance, and therefore the productivity of the workforce. Training and development usually come in the form of orientation, skills training and executive development. Investments made in training and development often ultimately translate into effectiveness and superior market-place performance for firms. This activity has implications, not just for raising employees' skills levels, but also for increasing their motivation - a factor that is critical for job satisfaction, productivity and long term commitment to the organization.

The employee relations activities comprise a set of actions and programs aimed at facilitating commitment, loyalty, a sense of belongingness and cooperation on the part of employees. By ensuring employee protection, safety and health, transparency, equity and fairness (particularly in compensation, training and development, and discipline), cooperation and assistance, communication (constant update of policies and other information) and creating a generally good-place-to-work-in, an HR manager helps in raising employees' perception of the organization's value and importance in the achievement of their individual goals. In a significant way, this ensures employees' fidelity to the organization and achievement of its set goals. Good employee relations practices usually guarantee minimization of conflicts between the internal stakeholders of the organization.

Performance management involves the measurement, evaluation and adjustment of specific areas of employees' performance to ensure that their activities and output contribute sufficiently to the achievement of organizational goals.

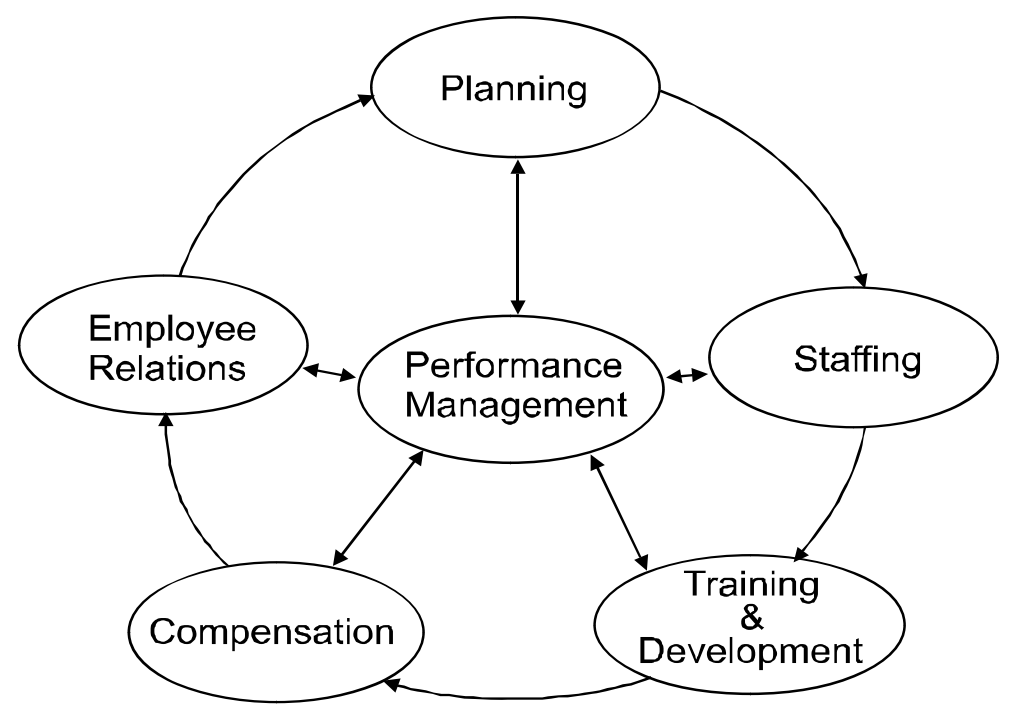

Figure 1. Human resource management continuum

\section{The Roles and Requirements of the HR Manager}

The human resource manager plays a number of roles in addition to carrying out or managing the aforementioned activities. For instance, the HR manager operates as a key advisor to the managers in other functional areas of the organization. The support offered in this regard is invaluable, as all the other areas virtually depend, for all their activities and operations, on the people the HR manager is responsible for bringing into the system. More critically, the HR manager becomes a coach and facilitator for the development of 
people-management skills in the line managers - who are increasingly finding themselves involved in the management of people, and whose productivity they are being held responsible for. Another major role played by the HR manager is that of facilitating ethical behavior on the part of employees. Here, the manager constantly creates opportunities using the various channels available to ensure that the organization's core ethical values, principles and expectations are adequately communicated and inculcated to its members. The HR manager is also responsible for facilitating the creation of high performance work systems in which the organizational structure, technology, work processes and people function together to deliver some competitive advantage for the organization in the market place. To be effective in playing these roles, the HR manager often needs to be equipped with the requisite technical, human relations, leadership and decision-making skills. These skills are especially essential in building and sustaining quality workforce, constructing attractive incentive schemes, and facilitating cooperation between management and union (Erasmus, Swanepoel, Wyk \& Schenk, 2004).

\section{Emerging Human Resource Management Concepts and Practices}

In order to position itself to sufficiently cope with and overcome the challenges posed by new developments, human resource management is evolving in its outlook, content and context. A number of human resource practices signal a new paradigm in the management of people in organizations. Key among these include: a shift of human resource management responsibility to line managers; development of the human resource management function as a business partner; change in language; building flexible, adaptable and multi-skilled teams and shift in focus to the customer (Lancourt \& Savage, 1995).

\section{(i) The shift of human resource management responsibility to line managers}

The need to move towards lean operating systems has necessitated the development of human resource management capabilities in line managers across organizations. This shift signals a whittling-down of the size and scope of human resource management as a separate and distinct organizational function. In its place, line operatives, who themselves deal directly with most of the employees, become empowered to perform most of the core HR activities, including hiring, performance management and training. HR managers restrict their activities to planning and managing compensation, and general coordination of HR decisions and actions. In addition to this, they coach the various line managers in these new or added responsibilities. This concept frees the HR manager from much of the basic technical tasks and allows for concentration on policy, planning and other conceptual HR issues.

\section{(ii) Development of the human resource management function as a business partner}

As a corollary to shifting HR responsibilities to line managers, firms that adopt this practice redefine the human resources function as a business partner of the organization. In this new role, the HR manager is essentially tasked with facilitating the smooth implementation of new strategies such as integration of acquired companies into the organization and helping in fitting-in the required technical skills for such sensitive and delicate activities as starting new plants or product lines.

\section{(iii) A change in organizational language}

Language represents a powerful tool for facilitating change in the orientation and direction of an organization. As organizational structures and infrastructures transform and the relationship between employees and managers evolve, so does it become important for the relational language and nomenclature to change for the key jobs. This is a powerful way of reshaping employees' mindset, while better aligning a number of the traditional functions with the new outlook and philosophy of modern firms, particularly those that are evolving into leaner and more people-friendly organizations. Here, words like members, associates, partners and co-workers replace such official descriptions as employees and staff. Similarly, coordinator, coach, leader and sponsor replace titles like manager and supervisor.

\section{(iv) Customer focus}

A recognition that the business is all about the customer (internal and external), and therefore a refocus on customers' needs and their satisfaction is one of the new directions that transforming organizations now take. This new thinking redirects the focus away from the managers to the customer, in terms of whom the employees are really serving. Overall, this approach drives employee attention and job satisfaction in a direction way that facilitates deeper attention on customer care and satisfaction.

(v) Building flexible, adaptable and multi-skilled workforce

Developing a workforce that is made up of a pool of highly versatile persons who have the skills and talent to perform different tasks is important for operating and maintaining lean systems. The process towards achieving 
this begins at the point of planning, recruitment and selection of only persons who can be readily re-tooled in new skills and areas of competences.

\section{Discussion and Conclusion}

In this paper an attempt has been made to identify a number of new human resource management approaches and practices. It is argued that where these measures are applied, significant improvements in the capabilities of the workforce of organizations can be expected. These improvements result in better performance by the organizations, expressed as an index of their profitability, innovation, productivity and growth. The challenge for human resource managers lies in how quickly they can move away from the stereotype of being administrators of compensation, gatekeepers and watchdogs of conditions of employment to that of leadership in helping organizational members develop their capabilities.

Adoption of the suggested new approaches and practices notwithstanding, a number of traditional human resource management practices still need to be strengthened. These include the continued building of quality workforce, provision of attractive incentive schemes and fostering cooperation between management-union in organizations. Additionally, organizations need to promote shared values and transformational leadership. Where organizational members share common values and their objectives align, the need for external control mechanism begins to diminish in importance in the management of people. In structural terms, the creation and maintenance of relatively flat hierarchical structures, which feature the use of teams, also facilitates efficient operation for organizations. Wastes, in terms of time and organizational resources, tend to reduce as decisional or managerial levels decrease. In this connection, flat structures facilitate closer interaction between organizational members and eliminate rigidities in their interaction. This close interaction is of enormous value for the bonding and effectiveness of work teams - which in turn supports the flat and lean organizational structure. Teams not only provide opportunities for shared experience, but are also potent in collapsing structural barriers between the various functional areas of an organization. Furthermore, they provide members with the opportunity to gain new knowledge or skills, as they move from one project to another. Also, by compensating staff for their skills rather than the specific jobs they are hired for, a high level of flexibility and task mobility becomes introduced under which people can be switched in an adaptive way across various jobs and positions. This strategy supports the team building principle or agenda of developing multi-skilled workforce.

Building a people-oriented organizational culture is also an imperative that competitive organizations need to focus on. An organizational philosophy that promotes and places emphasis on the welfare and well-being of employees is one that is likely to create a satisfied workforce. This satisfied workforce in turn is one that will concentrate on achieving customer satisfaction. Linked to this is a requirement to focus on becoming a learning organization, in which the continuous development and improvement of employees is a major human resource management task. When employees achieve superior levels of performance, their contributions need to be recognized and appropriately rewarded as a way of facilitating higher motivation.

The main limitation of this study is that it is conceptual and non-empirical. In order to establish the effect of the suggested approaches and practices presented in the paper, there is need for further empirical study. Nevertheless, as the propositions made are essentially recommendatory, and not prescriptive in nature, other measures that can be used complementarily with them are also encouraged.

\section{References}

Bratton, J., \& Gold, J. (1999). Human resource management: Theory and practice. Hampshire, UK: MacMillan Business.

Erasmus, B., Swanepoel, B., Wyk, M. V., \& Schenk, H. (2004). South African human resource management: Theory \& Practice. South Africa: Juta \& Co. Ltd.

Lancourt, J., \& Savage, C. (1995). Organizational transformation and the changing role of the human resource function. Compensation \& Benefits Management, 11(4). Retrieved from www.kee-inc/article.htm.

Milkovich, G. T., \& Boudreau, J. W. (2004). Personnel/Human Resource Management: A diagnostic approach (5th ed.). Illinois: Richard D. Irwin.

Noe, R. A., Hollenbeck, J. R., Gerhart, B., \& Wright, P. M. (2004). Fundamentals of human resource management. Boston: McGraw-Hill.

Oyesola, A. (2011, June 20). Managing health and safety in workplace: Employee’s perspective. Daily Sun, pp. $31 \& 33$. 